\title{
Several thoughts on class management work of college students
}

\author{
Yunfei Li, Wen Yan
}

\author{
Agricultural University of Hebei, Baoding, 071001, China \\ Keywords: college student; class management; class atmosphere; system construction
}

\begin{abstract}
: in recent years, as college enrollment expands, the quality of college students is uneven. Meanwhile, the class size is also on the rise, this leading to the increase in the difficulty of class management. Thus, this paper proposes in class management of college students, it is required to enhance entrance education and initial management of college students, pay high attention to cultivation of excellent class atmosphere, spare no effort to highlight self-control function of college class, strengthen college class system construction, improve quality of college class counselor and promote scientization and standardization of college class management.

At present, we are in the new period of construction of socialist market economy with Chinese characteristics. Sharp changes occur in the society. Profound changes have happened to ideology, values and life style of college students. Diversified development trend is shown. Relative to current situation of college student education, college student management problem becomes increasingly complex. Besides, college enrollment expansion results in the rise in the number of college students, and class management difficulty becomes more and more difficult. Therefore, college student managers must deeply ponder over and explore new approaches of class management of college class. Here, the author will conduct discussions form five aspects.
\end{abstract}

\section{To enhance entrance education and initial management of college students}

Nowadays, class management idea of many colleges still lags behind and cannot adapt actual situations of new generation of college students. Current college students are generally poor in social adaptation ability and have strong dependence. Most freshmen feel they can relax well after enrolling in colleges. Meanwhile, they generate fear mentality in the face of fierce employment pressure. Thus, it is difficulty for them to adapt new environment and new form. It is very necessary to enhance entrance education and initial management of college class. Firstly, it is required to grasp entrance education well to establish self-confidence of freshmen. Previously, college graduates were popular talents, and each employer would try all means to recruit and retain college students. However, as colleges increase enrollment for continuous ten years, the number of postgraduates and doctors is increasing. The employment rate of undergraduates presents the downtrend. Many college students cannot land satisfied jobs. So, employment problem after their graduation once made numerous college students feel confused. Thus, during entrance education period of college students, it is very urgent to establish self-confidence of freshmen. Secondly, it is required to enhance initial management. As a saying goes, all things are difficult before they are easy. From the middle school to the college, most college students are at loose ends. For example, new changes happen to their living habits, learning environment and interpersonal environment. It is hard for them to adapt new problems in new environment. For instance, the change of environment gives rise to self-evaluation imbalance, while learning discomfort leads to the rise in learning pressure. The differences between ideal and reality result in disappointment and confusion, while interpersonal discomfort causes loneliness and depression. Aiming at the above situations, it is required to enhance education of college students in living accommodation when they initially enroll in universities. In addition, colleges should pay much attention to learning atmosphere and discipline education so that freshman class can develop favorable learning and living habits. This is very vital for class management and development of college students. 


\section{To pay much attention to cultivation of excellent class atmosphere}

The study atmosphere of a college will have direct impacts on personal growth of college students and then further influence college development and social atmosphere to some extent. Thus, important significance of school atmosphere cultivation can be seen. School atmosphere consists of class atmosphere of each class. School atmosphere is external environment of class atmosphere, while class atmosphere is an important constituent part of school atmosphere. The two have the relationship between the whole and part. School atmosphere will certainly affect class atmosphere formation, while class atmosphere in turn will promote changes in school atmosphere. Class atmosphere is spiritual outlook reflected through long-term arduous and meticulous education and cultivation. Thus, standards need to be established, such as respecting teachers and paying attention to teaching, seeking the truth and being practical, and advancing actively and bravely. The selection standards of class atmosphere are the same with those of school atmosphere. Of course, new standards can be specified according to general opinions of classes, but these standards should not go against standards of school atmosphere. After standards of class atmosphere are specified, it is necessary to cultivate through daily work.

Firstly, it is required to attach importance to cultivation force of student leaders and facilitate them to give play to the example role. To form favorable class atmosphere, some must advocate and give play to the example role, i.e. class leaders. College students just enter colleges from senior high schools. When they become student leaders, it is hard to adapt role change in a short term. This is mainly because class activities are few in senior high schools. Besides, most activities are organized by class advisers. So, their organizing and coordinating abilities cannot be well trained and cultivated. Thus, we must attach great importance to cultivating class leaders. Students should be required to set strict demands on themselves in many aspects and set themselves examples to others. Improvement of personal prestige should be based on boosting class prestige. Student leaders should establish service awareness and submit to leadership of teachers and counselors. In addition, student leaders should better exert their subjective initiative.

Secondly, it is required to cultivate active and upward correct class public opinion. To form favorable class atmosphere, a class must cultivate correct class public opinion, while class public opinion can guide and restrain concrete behaviors of each member and a powerful education force. In a bid to cultivate positive and active class public opinion, it is required to carry out education of favorable school atmosphere and class atmosphere by utilization of ideological and political study, theme class meeting and class committee, or implement detailed discussions in allusion to an event so as to specify the right and wrong, make all have uniform understanding, guide public opinion to correct direction and form the effect of rewarding the good and restraining the evil. For example, for such phenomena as scribbling and stirring up troubles, colleges can make students understand this is a disciplinary offence behavior. Such phenomena occur due to low cultural quality of a few students. New generation of college students should draw a clear distinction with such behaviors, or else they will be scorned by others. In this way, correct public opinion forms. The phenomena of violating disciplines in college campus will naturally reduce.

Thirdly, it is required to strengthen class atmosphere inspection and supervision work, and grasp the degree. Excellent class atmosphere comes from persistent insistence. To deepen in insistence, regular supervision and inspection must be conducted. Contemporary college students generally have a wide range of interests and high enthusiasm, while their self-control ability and consciousness of responsibility are generally poor. Thus, ideological and political work cannot reach the effect of once and for ever. This requires enhancing inspection, supervision and guidance to make sure favorable class atmosphere can continue and develop. Meanwhile, during inspection and supervision, management tightness degree should be grasped well. Once management is too strict, requirements are too high. As time passes, college students will generate aversion mood. For instance, for the problem that a few college students are late for class occasionally, as long as they are unintentional, teachers should give full understanding and guide students in education process, rather than condemning them. Otherwise, college students may easily have rebellious mood, this 
increasing management difficulty. However, loose management means let things drift. As time passes, college student management will be out of control. Thus, forming stable class atmosphere becomes a mere formality.

\section{To spare no effort to highlight self-control ability of college class}

Self-management and self-education of college students are inevitable requirements of modern higher education in China and also the needs for cultivating pioneering and progressive personnel. In scientific and normative college class management, it is required to make college students learn self-education so as to reach self-discipline and self-improvement and really become masters of learning and life. It is required to give full play to self-control ability of college classes. This is an important guarantee of improving college class management. In traditional sense, class management is mainly centered by class adviser. Teachers often consider themselves to be authoritarians. They pay excessive attention to students' obedience. College students are often in passive and obedient status. However, in current society, such management mode falls behind. On the one hand, college students are not that obedient as before. They start to have unique views. On the other hand, college students educated under such management mode lack organization, coordination and innovation abilities. It is hard for them to adapt needs of modern social development. Only when college classes fully mobilize students' subjective initiative and make them really participate in class management and implement self-management can class management effects be better improved. To better exert class self-control function, colleges must pay high attention to improving students' self-control level. In other words, colleges should be devoted to cultivate students' self-management ability and implement self-government of class affair. This is also the goal of class management. Only in this way, management participation awareness of college students can be satisfied, and subjectivity function of college students can be better exerted so that college students can adapt future social competitions.

\section{To strengthen college class system construction}

To implement system construction in college class and carry out system management is not just the mark of class collective construction level, but also a vital move for developing excellent classes. Modern management system has provided good behavior standards and behavior control basis for class system construction so that college students can become autonomic from heteronomy. However, it is required to grasp the work in three aspects in each link. Firstly, systems should keep pace with college students. Under strict control of class system, it is required to reach there are rules to follow. It is required to make target management of college classes to really achieve standardization, institutionalization and routinization with the help of a series of rules and regulations. Secondly, rules and regulations should be operable. College class system should strive to be precise in the form, specific and feasible for the convenience of operation. Moreover, opinions should be widely solicited for college class system. Repeated demonstration should be conducted as far as possible. Based on overall considering advantages and disadvantages, class system should be formulated in combination of relevant regulations on administration of the college. In the meantime, in the process of executing class management regulations, it is required to carefully collect relevant materials, compare carefully, continuously modify, supplement and perfect them so as to make class rules and regulations more accord with actual conditions. Finally, college class system should comply with the fooling requirements: it should comply with requirements of Chinese laws and regulations as well of the college; class rules and regulations should be scientific, practically follow higher education rules, accord with physical and mental development features of colleges as well as features of college management; class rules and regulations should pay attention to education, start from actual management needs, and fully consider features of college management so as to better give pay to educational functions; moreover, class rules and regulations should be stable and continuously modified in the execution process; but it is required to maintain the stability of class rules and regulations which should not be given up halfway or changed at will. 


\section{To improve quality of college class adviser}

Theory quality is an essential quality of college class counselor. As a college class counselor, he should not just own theoretical knowledge in pedagogy and psychology, but also have a solid mastery of theories. In this way, they can better carry out creative work and help college students form correct outlook on life and values. In order to effectively improve work level, college class counselors should be diligent in learning and continuously boost their theoretical attainment. Meanwhile, class counselors should be provided with the ability to experience and observe thoughts and emotions as well as ideological information of college students so as to accurately master their real attitude and suit the remedy to the case. In view of this, class counselors should possess observation ability, organizing and coordinating ability, communication ability, oral expression ability and written expression ability, find, cultivate and apply excellent talents among students. Ideological and political level, work attitude, speech and behavior of college class counselors will influence college students. So, college class counselors should pay attention to improving their quality, form steady and rigorous style of work, influence college students through their personality charm and achieve the purpose of educating and guiding college students.

\section{Conclusions}

In general, college class management work must reflect various requirements of developing socialist market economy with Chinese characteristics and current characteristics of times owned by quality education. Meanwhile, it is required to continuously summarize and explore in practice and strive to achieve class management efficacy. College students are life entity full of vigor and vitality. It is required to continuously enhance class management work and accord with development needs of current times in allusion to actual situations of college students.

\section{References}

[1] Hu Xuesong, Study on problems and countermeasures of college class management [J]. Journal of Shangqiu Vocational and Technical College, 2012 (4)

[2] Cheng Min, On relationship between class management and personality development of college students [J]. Industrial \& Science Tribune, 2013 (1)

[3] Shen Yingda, Discussion on fine management of college students [J]. Petroleum Education, $2014(1)$

[4] Zhao yue, Analysis of effective measures of self-management of college class [J]. Science and Technology Innovation Herald, 2014 (6)

[5] Lin Furong, Analysis of problems and countermeasures of college class management [J]. Intelligence, 2014 (23) 